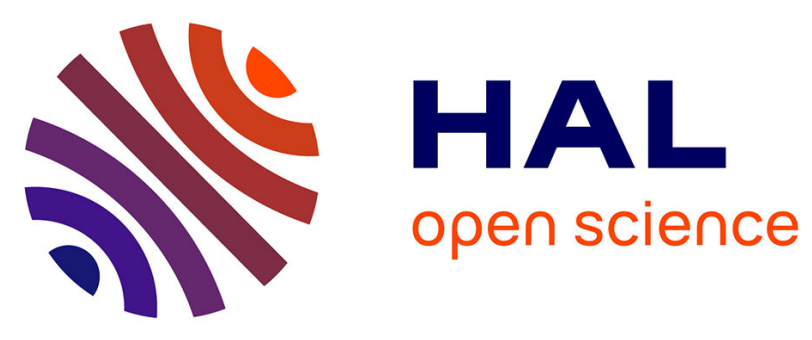

\title{
EmbR2, a structural homologue of EmbR, inhibits the Mycobacterium tuberculosis kinase/substrate pair PknH/EmbR
}

Virginie Molle, Robert C Reynolds, Luke J Alderwick, Gurdyal S Besra, Alain J Cozzone, Klaus Fütterer, Laurent Kremer

\section{To cite this version:}

Virginie Molle, Robert C Reynolds, Luke J Alderwick, Gurdyal S Besra, Alain J Cozzone, et al.. EmbR2, a structural homologue of EmbR, inhibits the Mycobacterium tuberculosis kinase/substrate pair PknH/EmbR. Biochemical Journal, 2008, 410 (2), pp.309-317. 10.1042/BJ20071384. hal00478893

\section{HAL Id: hal-00478893 \\ https://hal.science/hal-00478893}

Submitted on 30 Apr 2010

HAL is a multi-disciplinary open access archive for the deposit and dissemination of scientific research documents, whether they are published or not. The documents may come from teaching and research institutions in France or abroad, or from public or private research centers.
L'archive ouverte pluridisciplinaire HAL, est destinée au dépôt et à la diffusion de documents scientifiques de niveau recherche, publiés ou non, émanant des établissements d'enseignement et de recherche français ou étrangers, des laboratoires publics ou privés. 


\section{EmbR2, a structural homologue of EmbR, inhibits the Mycobacterium tuberculosis kinase/substrate pair PknH/EmbR}

\section{Virginie Molle*, Robert C. Reynolds ${ }^{\dagger}$, Luke J. Alderwick ${ }^{\ddagger}$, Gurdyal S. Besra ${ }^{\ddagger}$ Alain J. Cozzone*, Klaus Fütterer*, and Laurent Kremer ${ }^{\S}, \|, \pi$}

\footnotetext{
*Institut de Biologie et Chimie des Protéines, Université de Lyon I-CNRS, Lyon, France.

${ }^{\dagger}$ Drug Discovery Division, Southern Research Institute, PO Box 55305, Birmingham, AL 352255305, USA.

${ }^{\ddagger}$ School of Biosciences, University of Birmingham, Edgbaston, Birmingham, B15 2TT, UK.

${ }^{\S}$ Laboratoire de Dynamique des Interactions Membranaires Normales et Pathologiques, Université de Montpellier II et I, CNRS; UMR 5235, case 107, Place Eugène Bataillon, 34095 Montpellier Cedex 05, France.

॥INSERM, DIMNP, Place Eugène Bataillon, 34095 Montpellier Cedex 05, France.
}

๑Corresponding author. Mailing address: Laboratoire de Dynamique des Interactions Membranaires Normales et Pathologiques, Université de Montpellier II et I, CNRS; UMR 5235, case 107, Place Eugène Bataillon, 34095 Montpellier Cedex 05, France. Tel:(+33) 4671433 81; Fax: (+33) 4671442 86. E-mail: laurent.kremer@univ-montp2.fr

Running title: EmbR2 inhibits PknH autokinase activity 


\section{Synopsis}

EmbR is a transcriptional regulator which is phosphorylated by the cognate mycobacterial serine/threonine protein kinase $\mathrm{PknH}$. Recent studies demonstrated that PknH-dependent phosphorylation of EmbR enhances its DNA-binding activity and activates transcription of the embCAB genes encoding arabinosyltransferases which participate in arabinan biosynthesis. Herein, we identified a genomic region of 4425-bp, that is present in Mycobacterium tuberculosis CDC1551, but absent from M. tuberculosis H37Rv, comprising the MT3428 gene, which is homologous to embR. Homology modelling of the MT3428 gene product illustrated its close relationship (56\% identity) to EmbR, and was hence termed EmbR2. In marked contrast to EmbR, EmbR2 was not phosphorylated by $\mathrm{PknH}$, although it is a substrate of other $M$. tuberculosis kinases, including PknE and PknF. Tryptophan fluorescence emission of EmbR2 was monitored in the presence of three different $\mathrm{PknH}$-derived phosphopeptides and demonstrated that EmbR2 binds to at least two of the threonine sites known to undergo autophosphorylation in PknH. We observed that the capacity of EmbR2 to physically interact with PknH without being phosphorylated was a result of EmbR2-mediated inhibition of kinase activity: incubation of $\mathrm{PknH}$ with increasing concentrations of EmbR2 led to a dose-response inhibition of the autokinase activity, similarly to O6-cyclohexylmethylguanine, a known inhibitor of eukaryotic cyclin-dependent kinases. Moreover, EmbR2 inhibited PknH-dependent phosphorylation of EmbR in a dose-dependent manner. Together, these results suggest that EmbR2 is a regulator of $\mathrm{PknH}$ activation, thus directly participating in the control of the $\mathrm{PknH} / \mathrm{EmbR}$ pair and potentially in mycobacterial physiology/virulence of $M$. tuberculosis CDC1551.

Keywords: Mycobacterium, phosphorylation, Ser/Thr protein kinase, PknH, EmbR, EmbR2, inhibitor, FHA domain, structural model 


\section{Introduction}

Genes encoding functional Serine/Threonine Protein Kinases (STPKs) are ubiquitous in prokaryotic genomes, but little is known regarding their physiological substrates and their participation in bacterial signal transduction pathways and their regulation. Based on their genomic context, many of the 11 STPKs from Mycobacterium tuberculosis $(M$. $t b)$ were proposed to participate in regulation of diverse physiological functions [1]. An increasing body of evidence indicates that the STPKs play important roles in the physiology and virulence of $M$. $t b$ and are potential therapeutic targets for future drug development against tuberculosis [2]. Recent studies have provided evidence that at least two kinases, $\mathrm{PknG}$ and $\mathrm{PknH}$, play a role in the virulence of $M$. $t b$ [3-5]. PknG contributes to the survival of mycobacteria within macrophages by preventing fusion of phagosomes with lysosomes [5]. In contrast, it was demonstrated that a PknH mutant of $M$. $t b$ is hypervirulent in infected mice and it was proposed that PknH regulates intracellular bacterial growth particularly during the chronic phase [4].

Since EmbR (Rv1267c) and the sensor-like Ser/Thr kinase PknH (Rv1268c) are adjacent in the $M$. tuberculosis genome, we first investigated whether EmbR may represent an endogenous substrate of $\mathrm{PknH}$. We found that EmbR was phosphorylated by $\mathrm{PknH}$ in vitro, and that the interaction with the kinase was mediated by EmbR's C-terminal FHA (ForkHead Associated) domain [6]. FHA domains are small protein modules capable of mediating proteinprotein interactions through pThr recognition, and often participate in protein-protein interactions in STPK-dependent signal transduction pathways [7]. Truncation of the EmbR FHA domain or point mutations altering conserved residues in the phosphothreonine-binding pocket dramatically diminished PknH-mediated threonine phosphorylation of EmbR [6]. Elucidation of the three-dimensional structure of EmbR revealed that, in addition to the FHA domain, it possesses two major domains, an N-terminal winged helix-turn-helix DNA-binding domain followed by a central bacterial transcription activation (BTA) domain, suggesting that EmbR may act as a transcriptional regulator in $M$. $t b$ [8]. This was recently supported by the fact that phosphorylation of EmbR enhances its DNA binding activity towards promoter regions of embCAB genes [9]. The corresponding gene products are known to participate in the biosynthesis of arabinogalactan and lipoarabinomannan which are critical components of the mycobacterial cell wall [10-12]. The PknH-mediated increase in the transcription of embAB also alters resistance to ethambutol, a frontline antituberculosis drug known to target embAB [10, 11]. These results along with the in vivo up-regulation of PknH inside host macrophages [13] suggest 
a functionally relevant signalling mechanism involving the PknH-EmbR-EmbCAB. In addition, Sharma et al. demonstrated that the Ser/Thr protein kinases PknA and PknB also regulate the signalling pathway leading to EmbR phosphorylation [9].

In a related actinomycete, Corynebacterium glutamicum, phosphoproteome studies experimentally determined 120 unique Ser/Thr-phosphorylated proteins that are phosphorylated by only four STPKs [14]. In support of these results, using a bioinformatic approach, 40 potential PknH substrates were identified (including EmbR) in $M$. $t b$, and two of the newly predicted substrates were experimentally shown to be phosphorylated by $\mathrm{PknH}$ in vitro [15]. These two substrates, which lack an FHA domain, are Rv0681, a TetR-class transcription factor, and DacB1, a penicillin-binding protein [15]. The presence of a large number of FHA and nonFHA-containing substrates of PknH in $M$. tb suggests a possible participation of this kinase in numerous signalling pathways. Since PknH appears as a key determinant of pathogen virulence [4], it is very likely that further characterization of the various endogenous substrates and regulatory mechanisms will increase our understanding of the physiology and pathogenicity of $M$. $t b$. One possible mechanism of regulating the phosphosignalling responses is to control the rate of phosphorylation of both the kinases and the substrates, which can be achieved in vitro and in vivo by Ser/Thr phosphatases. To date, only one Ser/Thr-phosphatase, termed PstP, has been found in the $M$. $t b$ genome mediating dephosphorylation of kinases [16] as well as substrates [17]. However, it is unlikely that PstP represents the only factor that controls the phosphorylation status of all eleven STPKs and all substrates in vivo. We reasoned that additional mechanisms of controlling/regulating the phosphorylation status of PknH may exist. In Streptomyces coelicolor A3(2), the KbpA protein which is involved in actinorhodin production has been demonstrated to bind to the STPK AfsK and to inhibit its autophosphorylation activity at serine and threonine residues [18]. KbpA also inhibited phosphorylation of AfsR, which is the substrate of AfsK, presumably because KbpA inhibited the conversion from the inactive nonphosphorylated form of AfsK to the active phosphorylated form [18].

In light of this study, we extended our previous work on the characterization of the $\mathrm{PknH} /$ EmbR pair by identifying and characterizing a protein from $M$. tuberculosis CDC1551 that interferes specifically with the autokinase activity of $\mathrm{PknH}$, subsequently inhibiting $\mathrm{PknH}$ dependent phosphorylation of EmbR. This protein, termed EmbR2, closely related to EmbR, is capable of interacting with $\mathrm{PknH}$, but cannot be phosphorylated by this kinase. We predict that this protein would represent a bait for $\mathrm{PknH}$ and may represent a novel mechanism of regulation of the PknH/EmbR couple. 


\section{Materials and Methods}

\section{Bacterial strains, plasmids, and growth conditions}

Overproduction of EmbR2 was performed in Escherichia coli strain C41(DE3) [19]. E. coli TOP-10 (Invitrogen) was used to propagate plasmids in cloning experiments. All strains were grown and maintained at $37^{\circ} \mathrm{C}$ in LB medium supplemented with either $25 \mu \mathrm{g} / \mathrm{ml}$ kanamycin or $100 \mu \mathrm{g} / \mathrm{ml}$ ampicillin, when required. Plasmids pET28a and pCR-BluntII-TOPO were purchased from Novagen and Invitrogen, respectively.

\section{Expression and purification of GST-tagged Ser/Thr protein kinases from M. tuberculosis}

Plasmids designed to express the eight catalytic domains of Ser/Thr protein kinases (PknA, PknB, PknD, PknE, PknF, PknH, PknK, and PknL) fused to glutathione-S-transferase (GST) were constructed by PCR amplification using $M$. tuberculosis H37Rv genomic DNA as a template as described previously [17]. Kinases were purified using glutathione-Sepharose 4B matrix as reported earlier [17].

\section{Expression and purification of a $\mathrm{His}_{6}$-tagged $\mathrm{EmbR}$ and EmbR2}

Construction of pET28a-embR expression vector was used to overproduce EmbR in C41(DE3) E. coli cells as reported earlier [6]. The embR2 gene (MT3428), with appropriate sites at both ends, was synthesized by PCR amplification using M. tuberculosis CDC1551 genomic DNA as a template and the following primers: embR2-up 5'-CC CAT ATG GCC CGA AAC GAA CTC CG-3' (NdeI site underlined) and embR2-lo 5'-GGA TCC TAA CGG CCC GAT TCG TG-3' (BamHI underlined). This 1156-bp DNA fragment was directly ligated into the pCR-BluntIITOPO, yielding the PCRII-BluntII-embR2 construct. The embR2 insert was then extracted and purified following restriction of pCRII-BluntII-embR2 with NdeI and BamHI, and subsequently

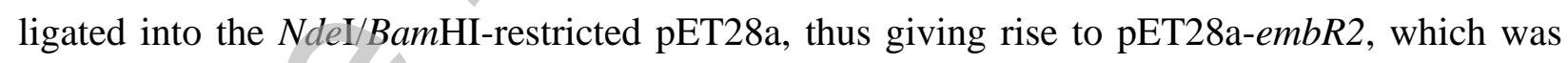
used to transform E. coli C41(DE3) cells. Cultures were incubated at $37^{\circ} \mathrm{C}$ under shaking until $A_{600}$ reached 0.5 . IPTG was then added at a final concentration of $1 \mathrm{mM}$, and growth was continued for an additional $3 \mathrm{~h}$ at $30^{\circ} \mathrm{C}$. Cells were harvested by centrifugation at $6,000 \times \mathrm{g}$ for $10 \mathrm{~min}$, washed in $10 \mathrm{ml}$ of buffer A (50 mM Tris/HCl pH7.5; $150 \mathrm{mM} \mathrm{NaCl} ; 10 \%$ glycerol; 1 mM $\beta$-mercaptoethanol; 1 mM EDTA; $10 \mathrm{mM}$ imidazole) containing DNAse, RNAse and a protease inhibitor cocktail (Roche). Bacteria were then disrupted in a French pressure cell and the resulting extract was centrifuged for $30 \mathrm{~min}$ at $27,000 \times g$ at $4^{\circ} \mathrm{C}$. The supernatant was 
collected and incubated for 2 hours at $4^{\circ} \mathrm{C}$ on a rotating wheel with Ni-NTA agarose (Qiagen) previously equilibrated with buffer A. After extensive washing with buffer A, bound proteins were eluted with elution buffer (50 mM Tris/HCl pH7.5; $150 \mathrm{mM} \mathrm{NaCl} ; 10 \%$ glycerol; $1 \mathrm{mM} \beta$ mercaptoethanol; 1 mM EDTA; $300 \mathrm{mM}$ imidazole). Pure EmbR2 fractions were pooled, dialyzed against $50 \mathrm{mM}$ Tris/HCl pH7.5, $150 \mathrm{mM} \mathrm{NaCl}, 10 \%$ glycerol, $1 \mathrm{mM}$ mercaptoethanol, $1 \mathrm{mM}$ EDTA to remove imidazole and stored at $-20^{\circ} \mathrm{C}$ until further use.

\section{Site-directed mutagenesis}

Site-directed mutagenesis was carried out based on PCR amplification. A first set of PCR amplifications was generated using pET28a-embR2 as a template along with the primer pair,

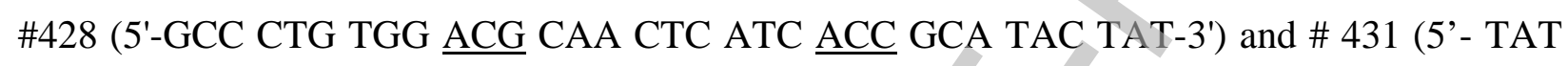
GGA TCC CTA ACG GCC CGA TTC GTG CGG -3') to generate embR2-R204T/A208T. This PCR product was then used as a primer in a second round of PCR amplification in combination with primer \#430 (5’- TAA TAG CT CAT ATG GCC CGA AAC GAA CTC CGG TTC-3') to generate the entire 1146-bp embR2 gene. This DNA fragment, containing the appropriate sites at both ends, was restricted by NdeI and BamHI (sites italicized) and ligated in the NdeI/BamHIrestricted pET28a, generating pET28a-embR2-R204T/A208T. The nucleotide changes in the different primers to allow specific amino acid replacement are underlined. Mutations were verified by DNA sequencing. The His-tagged EmbR2 mutant protein was overexpressed and purified as described above.

\section{In vitro kinase assay}

In vitro phosphorylation of about $1 \mu \mathrm{g}$ (15 pmol) of each STPK was carried out for 15 min at $37^{\circ} \mathrm{C}$ in a reaction mixture $(20 \mu \mathrm{l})$ containing buffer P $(25 \mathrm{mM}$ Tris-HCl, pH 7.0; $1 \mathrm{mM}$ DTT; 5 $\mathrm{mM} \mathrm{MgCl} 2 ; 1 \mathrm{mM}$ EDTA) with $200 \mu \mathrm{Ci} / \mathrm{ml}\left[\gamma_{-}{ }^{33} \mathrm{P}\right] \mathrm{ATP}$. Phosphorylation of EmbR or EmbR2 was performed with $3 \mu \mathrm{g}$ (66 pmol) of EmbR or EmbR2 in $20 \mu \mathrm{l}$ of buffer P with $200 \mu \mathrm{Ci} / \mathrm{ml}[\mu$ $\left.{ }^{33} \mathrm{P}\right] \mathrm{ATP}$ and $250 \mathrm{ng}$ of kinase for $15 \mathrm{~min}$ at $37^{\circ} \mathrm{C}$. In vitro inhibition assays were carried out with 0.5 to $3 \mu \mathrm{g}$ of EmbR2 $(0.55 \mu \mathrm{M}$ to $3.3 \mu \mathrm{M})$ or with 5 to $100 \mu \mathrm{M}$ of O6cyclohexylmethylguanine. The reaction was stopped by addition of an equal volume of $2 \mathrm{X}$ sample buffer and the mixture was heated at $100^{\circ} \mathrm{C}$ for $5 \mathrm{~min}$. After electrophoresis, gels were soaked in $16 \%$ TCA for $10 \mathrm{~min}$ at $90^{\circ} \mathrm{C}$, dried and exposed to films. Intensity of the radioactivity was measured with a Molecular Dynamics Typhoon phosphoimager. 


\section{Phosphopeptide binding assay}

Intrinsic Trp-fluorescence emission was measured between 300 and $400 \mathrm{~nm}$ (scan speed 100 $\mathrm{nm} / \mathrm{min}$ ), using a Perkin Elmer Luminescence Spectrometer LS 50B, exciting the sample at a wavelength of $295 \mathrm{~nm}$. Spectra were recorded for each peptide aliquot $(1 \mu \mathrm{l})$ added to $400 \mu \mathrm{l}$ of a $5 \mu \mathrm{M}$ solution of EmbR2, until reaching a final peptide concentration of $0.5 \mathrm{mM}$ (11 additions). A plot of fluorescence intensity at $330 \mathrm{~nm}$ vs. peptide concentration (3 independent experiments) resulted in a binding isotherm that was fitted to a one-site saturation model (SigmaPlot, Systat Software Inc.).

\section{Analysis of the phosphoamino acid content of proteins}

Phosphoamino acid analysis of the EmbR or EmbR2 proteins labelled in vitro with either PknE, PknF or PknH was performed as previously described [20].

\section{Homology model of EmbR2}

A homology model of the molecular structure of Mt-CDC1551 EmbR2 was derived based on the crystal structure of EmbR bound to the phosphopeptide SLEVpTEADT [8]. Models were obtained from several web-based modelling servers, including Swiss-Model [21], Geno3D [22], and 3D-JIGSAW [23]. The homology models were analyzed in comparison to the chain A complex of the phosphopeptide-bound structure of EmbR (pdb entry 2FF4, [8]).

\section{Synthesis of O6-cyclohexylmethylguanine}

The target sample was prepared by the method of Arris et al. [24]. $\mathrm{CHCl}_{3}: \mathrm{MeOH}$ (20:1) was used for purification via silica gel column chromatography yielding a single spot on thin layer chromatography: white solid, yield 66\%, mp 202-204 ${ }^{\circ} \mathrm{C}$ (dec.). ${ }^{1} \mathrm{H}$ NMR (300 MHz, Me $2 \mathrm{SO}-d_{6}$ ) d 12.38 ppm (bs, 1H, NH), 7.79 (s, 1H, H-8), 6.21 (bs, 2H, $\mathrm{NH}_{2}$ ), 4.20 (d, 2H, $-\mathrm{OCH}_{2^{-}}, \mathrm{J}=$ 6.1Hz), 182-162 (m, 6H, cyclohexyl H’s), 1.32-0.97 (m, 5H, cyclohexyl H’s). FABMS m/z: 248 $(\mathrm{M}+\mathrm{H})^{+}$. HRMS (ESI) calcd for $(\mathrm{M}+\mathrm{H})^{+}\left(\mathrm{C}_{12} \mathrm{H}_{17} \mathrm{~N}_{5} \mathrm{O}\right)$ 248.15059, found 248.15083. 


\section{Results and Discussion}

\section{Identification of EmbR2 in M. tuberculosis CDC1551}

In this study, we extended our previous studies by deciphering a new mechanism of regulation of phosphorylation of EmbR by $\mathrm{PknH}$. To this end, we first explored the genome of $M$. tb strain CDC1551 which, in contrast to the laboratory strain $M$. $t b \mathrm{H} 37 \mathrm{Rv}$, is involved in a recent cluster of tuberculosis cases and is known to be transmissible and virulent in humans [25]. The CDC1551 strain appears to be highly infectious in humans, is comparable in virulence to strain H37Rv in animal models [26], and has greater immunoreactivity than H37Ry and other clinical strains due to increased induction of TNF- $\alpha$, IL-6, IL-10, and IL-12 [27]. We identified a genomic region of 4425-bp that is present in CDC1551, but absent from $M$. $t b$ strain H37Rv, comprising the MT3428 gene [28] (Figure 1A). The insertion sequence IS6110 is the principal epidemiological marker for $M$. $t b$. A number of the insertions and deletions were associated with this insertion sequence, suggesting a role for this element in genome plasticity [29]. The presence in H37Rv of IS6110 lacking the 3- to 4-bp direct repeat directly adjacent to the deleted region relative to strain CDC1551 indicates that this deletion was associated with a possible mechanism of homologous recombination between nearby IS6110 elements [30]. We also found the MT3428 gene in other mycobacterial species, including M. bovis and M. bovis BCG (data not shown). MT3428, annotated as a putative transcriptional regulator, is highly homologous to EmbR. Indeed, the amino acid sequences of $M$. $t b$ H37Rv EmbR and $M$. $t b$ CDC1551 MT3428 (termed EmbR2) align with 55\% sequence identity over 381 residues (alignment using ClustalW, Figure $1 \mathrm{~B})$. The alignment is almost free from insertions and deletions. A single-residue gap in the FHA domain of EmbR2 maps to residue 300 (EmbR), while an N-terminal 5-residue deletion is located within the first eight residues in the sequence. In contrast to $e m b R$, which is genetically linked to $p k n H[6,31]$, embR2 is found to be genetically distant from $p k n H$.

We have generated homology models of EmbR2 based on our recently determined high resolution X-ray crystal structure of EmbR [8]. This seemed justified based on the high level of sequence identity and the very good resolution of the template structures (PDB: 2FEZ $2.0 \AA$, 2FF4 $1.9 \AA$ ). Algorithm-specific bias of the modeling outcome was minimized by generating models using a range of modeling servers. As expected, all models display a conserved backbone conformation for the N-terminal DNA-binding, the central BTA and the C-terminal FHA domain (Figure 1C). The models only diverge slightly around residue 294, where the FHA domain of EmbR2 lacks a residue relative to EmbR. This model clearly confirms the characterization of 
EmbR2 as a structural homologue of EmbR. We, thus, addressed the question whether crossregulation/interaction between these two proteins with $\mathrm{PknH}$ would occur.

\section{EmbR2 is not phosphorylated by PknH}

We first investigated whether EmbR2 represents a substrate of $\mathrm{PknH}$. To this end, $\mathrm{PknH}$ was expressed as a GST fusion [6], whereas EmbR and EmbR2 were expressed and purified as Histag fusions. When incubated with purified EmbR in the presence of $\left[\gamma_{-}{ }^{33} \mathrm{P}\right] \mathrm{ATP}, \mathrm{PknH}$ was able to phosphorylate EmbR, consistent with our previous results (Figure 2) [6]. In stark contrast, EmbR2 was not phosphorylated by PknH in vitro (Figure 2). This was rather unexpected given the high degree of sequence and structural conservation between these two proteins, an identical domain organisation and invariance of three key residues in the FHA domain (Arg312, Ser326 and Asn348) that are required for recognition of EmbR by PknH [6].

In their attempt to identify endogenous substrates of the PknH kinase, Zheng et al. searched the $M . t b$ genome database for open reading frames containing sequences similar to the motif TQLGT which encompasses a site of autophosphorylation in the activation loop of PknH, reasoning that the autophosphorylation and kinase activity may target similar amino acid motifs [15]. This allowed the identification of 40 putative substrates, including EmbR (containing a TQLIT motif), Rv0681 (containing a TQLGT motif) and DacB1 (containing a TQIGT motif). Substitution of the first Thr residue in this motif by an Ala residue completely abolished Rv0681 phosphorylation by $\mathrm{PknH}$, whereas in the case of EmbR and DacB1 phosphorylation by PknH was significantly reduced compared to the wild-type proteins [15]. EmbR2 contains a RQLIA motif instead of the TQLIT motif present in EmbR (Figure 1B). To investigate the possibility that absence of phosphorylation of EmbR2 by PknH correlates with the lack of the TQLIT motif, both the Arg204 and Ala208 were simultaneously replaced by two Thr residues to restore a genuine TQLIT motif within EmbR2. However, when tested in the presence of $\left[\gamma^{33} \mathrm{P}\right] \mathrm{ATP}$, PknH still failed to phosphorylate the EmbR2-R204T/A208T mutant (Figure 2). This indicates that the lack of a TQLGT motif in EmbR2 is not responsible for the absence of phosphorylation by $\mathrm{PknH}$.

\section{STPK-mediated phosphorylation of EmbR and EmbR2}

Overlapping substrate specificity of different $M$. $t b$ kinases has been reported earlier [17, 32, 33]. This prompted us to investigate whether EmbR2 could be phosphorylated by other $M$. $t b$ STPKs. EmbR2 was found to be phosphorylated by PknE and PknF (Figure 3A). Whereas PknF phoshorylates EmbR and EmbR2 equally well, PknE preferentially phosphorylates EmbR over 
EmbR2. In marked contrast, PknH is unable to phosphorylate EmbR2, but phosphorylates EmbR, similarly to PknE/F. This suggests different levels of substrate specificity of the different STPKs. A corollary, arising from these experiments is that EmbR and EmbR2, as they interact with multiple STPKs, may be regulated by multiple signals. Although a complex network of interactions between EmbR/EmbR2 and the different STPKs may exist, it remains to be established whether this STPK cross-talk occurs in vivo.

We next analysed the nature of the phosphorylated amino acid residues in EmbR/EmbR2 after in vitro phosphorylation with PknE, PknF or PknH. Following incubation with the kinases and $\left[\gamma-{ }^{33} \mathrm{P}\right] \mathrm{ATP}$, labeled proteins were separated by SDS-PAGE, excised, and subjected to acid hydrolysis. Figure 3B shows that, in agreement with our previous results [6], EmbR was phosphorylated by $\mathrm{PknH}$ only on threonine residues. However, analysis of the phosphoamino acid content of PknE-phosphorylated EmbR revealed that phosphorylation occurs on both threonine and serine residues, whereas PknF phosphorylated EmbR only on serine residues. These unexpected results prompted us to explore the phosphoamino content of the different Pkn/EmbR2 couples. Whereas EmbR2 was preferentially phosphorylated at threonine residues in the presence of PknE (with minor amounts of phosphoserine being detected), it was mainly phosphorylated at serine residues in the presence of PknF. As for EmbR, these results show that the nature of the phosphorylation sites is kinase-dependent. Furthermore, comparison of the phosphoamino profiles of EmbR and EmbR2 in relation with the different kinases also revealed that the nature of the phosphorylation sites is also dependent of the substrate. PknF phosphorylates EmbR strictly at serines, whereas PknF phosphorylates EmbR2 at both serines and threonines.

\section{Physical interaction between EmbR2 and PknH-derived phosphopeptides}

PknH was shown to possess autokinase activity on nine Ser and Thr residues [6, 34] and one of the Thr sites located within the kinase activation loop, Thr170, is required for PknH-mediated phosphorylation of EmbR [6]. As EmbR2 contains three Trp residues, we assessed ligandbinding by intrinsic Trp fluorescence. Intensity of Trp fluorescence emission at $330 \mathrm{~nm}$ was monitored as a function of concentration of three different PknH-derived phosphopeptides (DEKLPTQLGT containing the pThr170, TQLGPTAVGT containing the pThr174, DSAGpTLVSS containing the pThr222) as well as using a non-specific phosphopeptide derived from the high-affinity ligand of the FHA domain of the yeast Rad53p check-point kinase [7] (SLEVPTEADT). Changes of the emission intensity at $330 \mathrm{~nm}$ with increasing peptide concentrations reflect ligand binding, and the equilibrium dissociation constant $\mathrm{Kd}$ can be 
derived by fitting the resulting binding isotherm (Table 1). Each of the phosphopeptides bound with an equilibrium dissociation constant $\left(\mathrm{K}_{\mathrm{d}}\right)$ in the order of $15 \mu \mathrm{M}$. This is in marked contrast to binding data obtained with EmbR, where only the Rad53p-derived peptide caused a measurable change in the emission signal, indicating a $\mathrm{K}_{\mathrm{d}}$ of about $175 \mu \mathrm{M}$ [8]. Therefore, these results suggest that EmbR2 binds to at least two of the threonine sites known to undergo autophosphorylation in $\mathrm{PknH}$ [34].

Overall, the absence of PknH-mediated phosphorylation of EmbR2 despite low- $\mu \mathrm{M}$ interaction of the latter with at least three likely docking sites on the kinase, lead us to hypothesise that EmbR2 may not act as a substrate of PknH but rather as an inhibitor.

\section{Selective inhibitory effect O6-cyclohexylmethylguanine towards $M$. $t b$ kinases}

Cyclin-dependent kinases are increasingly recognized as important targets for therapeutic intervention in various proliferative disease states, including cancer [35]. O6cyclohexylmethylguanine has been reported as a newly discovered ATP-competitive purinebased inhibitor of CDK1/cyclin B1 and CDK2/cyclin A3, the O6 substituent occupying the kinase ribose binding sites [24, 36]. Notably, screening of a small library of approximately 5,000 compounds from Southern Research through the Tuberculosis Antimicrobial Acquisition and Coordinating Facility (www.taacf.org) identified a small number of 6-alkylthio- and O6-alkylpurines as well as 2,4-disubstituted- and 2,4,6-trisubstituted pyrimidines that were relatively active versus $M$. $t b \mathrm{H} 37 \mathrm{Rv}$ in vitro [37]. A cheminformatic search of the scaffolds suggested that these simple analogs may be ATP-competitive inhibitors of signaling kinases in $M$. $t b$. Recent publications support that these purine and pyrimidine scaffolds show broad and excellent antitubercular activity [38-40], and, in certain cases, antibacterial and enzymatic activity versus ATP-requiring bacterial kinases. Preliminary screening of several active samples from the TAACF in vitro screen identified the reported ATP-competitive CDK inhibitor O6cyclohexylmethylguanine as a potential inhibitor of PknH (data not shown). Thus, we tested the capacity of O6-cyclohexylmethylguanine (Figure 4A) to interfere with the autokinase activity of eight M. $t b$ STPKs in vitro. The catalytic domains of the kinases were purified as GST-fusion proteins [17] and incubated individually with $\left[\gamma^{33} \mathrm{P}\right] \mathrm{ATP}$ in the absence or presence of $50 \mu \mathrm{M}$ O6-cyclohexylmethylguanine. Figure 4A shows that this compound selectively inhibited the various kinases. Whereas the drug did not appreciably alter the activity of PknA, PknB, PknF, PknK or PknL, it exhibited a potent inhibitory effect on $\mathrm{PknH}$ and $\mathrm{PknE}$, and completely abrogated autophosphorylation activity of PknD. Comparative sequence analysis allowed 
grouping of the eleven $M$. $t b$ kinases into three distinct homology clusters ( $\mathrm{PknA} / \mathrm{B} / \mathrm{L}, \mathrm{PknF} / \mathrm{I} / \mathrm{J}$ and $\mathrm{PknD} / \mathrm{E} / \mathrm{H}$ ), while the two soluble enzymes (PknG and PknK) stand apart from all the others [2, 41]. Our results clearly indicate that O6-cyclohexylmethylguanine exhibits specific activity against the third group of kinases only, supporting the notion that $\mathrm{PknD} / \mathrm{E} / \mathrm{H}$ belong to the same clade. It also demonstrates the feasibility to design inhibitors that will target specifically one clade rather than another. This selectivity is of particular interest since signalling elements, including STPK, may represent a new class of attractive targets, and the expertise in designing such inhibitors for eukaryotic STPKs represent an intense research area [42] and could be exploited for the development of new antitubercular drugs.

Figure 4B (left panels) shows that O6-cyclohexylmethylguanine inhibited PknH autokinase activity in a dose-dependent fashion, with an $\mathrm{IC}_{50}$ value of around $5 \mu \mathrm{M}$. This prompted us to examine whether EmbR2 alters the autophosphorylation activity of $\mathrm{PknH}$ by incubating the kinase with increasing concentrations of EmbR2 in the presence of $\left[\gamma_{-}{ }^{33} \mathrm{P}\right] \mathrm{ATP}$. Figure $4 \mathrm{~B}$ (right panels) demonstrated inhibition of the autokinase activity of $\mathrm{PknH}$ in a dose-responsive manner, similarly to O6-cyclohexylmethylguanine. The $\mathrm{IC}_{50}$ value of EmbR2 was around $1.1 \mu \mathrm{M}(1 \mu \mathrm{g}$ of EmbR2 in the conditions used), thus indicating that a 5-fold excess of EmbR2 at a molar level was sufficient to inhibit $50 \%$ of the kinase activity of $\mathrm{PknH}$.

\section{EmbR2 inhibits PknH-dependent phosphorylation of EmbR}

It is known that activation of kinases often depends on regulatory processes involving phosphorylation/dephosphorylation through an autocatalytic mechanism. For instance, the activation loop is a major control element of an active/inactive conformational switch in numerous kinases [43], and the conformation of the activation loop often depends on the phosphorylation state [44]. Based on structural studies, it is thought that the activation loop controls both the accessibility to the catalytic site and the binding of the substrate. Combining on-target dephosphorylation/MALDI-TOF MS and LC-ESI/MS/MS has recently allowed the identification of nine phosphorylation sites in $\mathrm{PknH}$ [34] resulting from autophosphorylation, a prerequisite to its kinase activity. Since EmbR2 inhibits autophosphorylation of PknH, PknHdependent phosphorylation of EmbR could be dependent on the presence of EmbR2. Figure 5 clearly shows a dose-dependent inhibition of EmbR phosphorylation with increasing concentrations of EmbR2. However, when EmbR2 was replaced by an unrelated protein, for instance GST, there was no inhibitory effect on EmbR phosphorylation, thus demonstrating that the inhibitory effect was specific to EmbR2. These results suggest that, in the reaction mixture 
containing $\mathrm{PknH}$ and EmbR, EmbR2 inhibited the phosphorylation of EmbR by PknH, presumably because EmbR2 prevents the conversion from the inactive non-phosphorylated form of $\mathrm{PknH}$ to the active phosphorylated form. It is noteworthy that a similar mechanism of regulation has been reported in S. coelicolor A3(2), in which the KbpA protein binds to and inhibits autophosphorylation of AfsK as well as phosphorylation of AfsR, the substrate of AfsK [18].

\section{Concluding remarks}

The cell wall of pathogenic mycobacteria undergoes continuous changes in the course of growth, intramacrophagic survival or during infection in response to environmental changes [45] and many of the environmental stimuli are communicated within mycobacteria by sensor kinases present on the mycobacterial membrane [1]. $\mathrm{PknH}$ is unique to pathogenic mycobacteria, which is induced on infection of macrophages with $M$. tb [13]. The embCAB operon encoding arabinosyltransferases was identified as the cellular target of EmbR in M. tb [9]. PknHdependent phosphorylation of EmbR enhances the DNA binding activity of EmbR towards promoter regions of $e m b C A B$ genes. The consequent enhanced transcription of $e m b C$ results in a higher ratio of lipoarabinomannan (LAM) to lipomannan (LM) [9], which are two major cell wall lipoglycans. These complex molecules are important determinants in the mycobacterial physiology and in the modulation of the host immune system during disease progression [46]. Furthermore, PknH expression modestly alters ethambutol resistance by virtue of its ability to increase the transcription of the embA and $e m b B$ genes [9]. Together, this establishes that embCAB activation is controlled by EmbR phosphorylation and connects the LAM/LM ratio with the phosphorylation status of $\mathrm{PknH}$. However, little is known with respect to the regulation processes controlling $\mathrm{PknH}$ activation. Although this could be achieved (at least partially) by phosphorylation/dephosphorylation via the action of the Ser/Thr phosphatase PstP [16, 17], this study also suggests that EmbR2 could be a key regulator of PknH activation. We propose that PknH and EmbR form a pair participating in arabinan metabolism that can also be controlled by EmbR2, providing a novel mechanism of regulating phosphorylation of EmbR via PknH. In summary, this study describes an additional level of regulation of mycobacterial STPKs, which may explain how a limited number of kinases participate in many complex signalling pathways. It has been proposed that the PknH-mediated signalling pathways contribute to the regulation of bacillary load during the infection process [4]. Upon infection in mice, the M. tb H37Rv $\Delta p k n H$ 
mutant survived to a higher load in the mouse organs, especially during the chronic stage of infection, indicating that $\mathrm{PknH}$ plays a role in regulating bacillary load to facilitate adaptation to the host environment during the infection process. In this context, in vivo expression of EmbR2 in $M$. $t b$ CDC1551 or in other pathogenic species such as M. bovis (which possesses an identical embR2 gene), could inhibit PknH activation, and consequently increase the virulence phenotype of these strains. Whether EmbR2 plays an in vivo inhibitory role in a negative feedback system in the $\mathrm{PknH} / \mathrm{EmbR}$ regulatory pathway and contributes to survival and hypervirulence in pathogenic mycobacteria remains to be determined .

\section{Acknowledgments}

This work was supported by the National Research Agency (ANR-06-MIME-027-01 to VM and LK). G.S.B. acknowledges support in the form of a Royal Society Wolfson Research Merit Award and a Personal Research Chair from Mr. James Bardrick, as a former Lister InstituteJenner Research Fellow, the Medical Research Council (UK), and the Wellcome Trust.

Licenced copy. Copying is not permitted, except with prior permission and as allowed by law. (C) 2007 The Authors Journal compilation ( 2007 Biochemical Society 


\section{References}

1 Av-Gay, Y. and Everett, M. (2000) The eukaryotic-like Ser/Thr protein kinases of Mycobacterium tuberculosis. Trends Microbiol. 8, 238-244

2 Wehenkel, A., Bellinzoni, M., Grana, M., Duran, R., Villarino, A., Fernandez, P., AndreLeroux, G., England, P., Takiff, H., Cervenansky, C., Cole, S. T. and Alzari, P. M. (2007) Mycobacterial Ser/Thr protein kinases and phosphatases: Physiological roles and therapeutic potential. Biochim. Biophys. Acta. In Press.

3 Cowley, S., Ko, M., Pick, N., Chow, R., Downing, K. J., Gordhan, B. G., Betts, J. C., Mizrahi, V., Smith, D. A., Stokes, R. W. and Av-Gay, Y. (2004) The Mycobacterium tuberculosis protein serine/threonine kinase PknG is linked to cellular glutamate/glutamine levels and is important for growth in vivo. Mol. Microbiol. 52, 1691-1702

4 Papavinasasundaram, K. G., Chan, B., Chung, J. H., Colston, M. J., Davis, E. O. and AvGay, Y. (2005) Deletion of the Mycobacterium tuberculosis pknH gene confers a higher bacillary load during the chronic phase of infection in BALB/c mice. J. Bacteriol. 187, 5751-5760

5 Walburger, A., Koul, A., Ferrari, G., Nguyen, L., Prescianotto-Baschong, C., Huygen, K., Klebl, B., Thompson, C., Bacher, G. and Pieters, J. (2004) Protein kinase G from pathogenic mycobacteria promotes survival within macrophages. Science 304, 1800 1804

6 Molle, V., Kremer, L., Girard-Blanc, C., Besra, G. S., Cozzone, A. J. and Prost, J. F. (2003) An FHA phosphoprotein recognition domain mediates protein EmbR phosphorylation by $\mathrm{PknH}$, a Ser/Thr protein kinase from Mycobacterium tuberculosis. Biochemistry 42, 15300-15309

7 Durocher, D., Taylor, I. A., Sarbassova, D., Haire, L. F., Westcott, S. L., Jackson, S. P., Smerdon, S. J. and Yaffe, M. B. (2000) The molecular basis of FHA domain:phosphopeptide binding specificity and implications for phospho-dependent signaling mechanisms. Mol. Cell 6, 1169-1182

8 Alderwick, L. J., Molle, V., Kremer, L., Cozzone, A. J., Dafforn, T. R., Besra, G. S. and Futterer, K. (2006) Molecular structure of EmbR, a response element of Ser/Thr kinase signaling in Mycobacterium tuberculosis. Proc. Natl. Acad. Sci. U S A 103, 2558-2563

9 Sharma, K., Gupta, M., Pathak, M., Gupta, N., Koul, A., Sarangi, S., Baweja, R. and Singh, Y. (2006) Transcriptional control of the mycobacterial embCAB operon by $\mathrm{PknH}$ through a regulatory protein, EmbR, in vivo. J. Bacteriol. 188, 2936-2944

10 Belanger, A. E., Besra, G. S., Ford, M. E., Mikusova, K., Belisle, J. T., Brennan, P. J. and Inamine, J. M. (1996) The embAB genes of Mycobacterium avium encode an arabinosyl transferase involved in cell wall arabinan biosynthesis that is the target for the antimycobacterial drug ethambutol. Proc. Natl. Acad. Sci. U S A 93, 11919-11924

11 Telenti, A., Philipp, W. J., Sreevatsan, S., Bernasconi, C., Stockbauer, K. E., Wieles, B., Musser, J. M. and Jacobs, W. R., Jr. (1997) The emb operon, a gene cluster of Mycobacterium tuberculosis involved in resistance to ethambutol. Nat. Med. 3, 567-570

12 Escuyer, V. E., Lety, M. A., Torrelles, J. B., Khoo, K. H., Tang, J. B., Rithner, C. D., Frehel, C., McNeil, M. R., Brennan, P. J. and Chatterjee, D. (2001) The role of the embA and $e m b B$ gene products in the biosynthesis of the terminal hexaarabinofuranosyl motif of Mycobacterium smegmatis arabinogalactan. J. Biol. Chem. 276, 48854-48862

Sharma, K., Chandra, H., Gupta, P. K., Pathak, M., Narayan, A., Meena, L. S., D'Souza, R. C., Chopra, P., Ramachandran, S. and Singh, Y. (2004) PknH, a transmembrane 
Hank's type serine/threonine kinase from Mycobacterium tuberculosis is differentially expressed under stress conditions. FEMS Microbiol. Lett. 233, 107-113

14 Bendt, A. K., Burkovski, A., Schaffer, S., Bott, M., Farwick, M. and Hermann, T. (2003) Towards a phosphoproteome map of Corynebacterium glutamicum. Proteomics 3, 16371646

15 Zheng, X., Papavinasasundaram, K. G. and Av-Gay, Y. (2007) Novel substrates of Mycobacterium tuberculosis PknH Ser/Thr kinase. Biochem. Biophys. Res. Commun. 355, 162-168

16 Boitel, B., Ortiz-Lombardia, M., Duran, R., Pompeo, F., Cole, S. T., Cervenansky, C. and Alzari, P. M. (2003) PknB kinase activity is regulated by phosphorylation in two Thr residues and dephosphorylation by PstP, the cognate phospho-Ser/Thr phosphatase, in Mycobacterium tuberculosis. Mol. Microbiol. 49, 1493-1508

17 Molle, V., Brown, A. K., Besra, G. S., Cozzone, A. J. and Kremer, L. (2006) The condensing activities of the Mycobacterium tuberculosis type II fatty acid synthase are differentially regulated by phosphorylation. J. Biol. Chem. 281, 30094-30103 Umeyama, T. and Horinouchi, S. (2001) Autophosphorylation of a bacterial serine/threonine kinase, AfsK, is inhibited by KbpA, an AfsK-binding protein. J. Bacteriol. 183, 5506-5512

19 Miroux, B. and Walker, J. E. (1996) Over-production of proteins in Escherichia coli: mutant hosts that allow synthesis of some membrane proteins and globular proteins at high levels. J. Mol. Biol. 260, 289-298

20 Grangeasse, C., Doublet, P., Vaganay, E., Vincent, C., Deleage, G., Duclos, B. and Cozzone, A. J. (1997) Characterization of a bacterial gene encoding an autophosphorylating protein tyrosine kinase. Gene 204, 259-265

21 Schwede, T., Kopp, J., Guex, N. and Peitsch, M. C. (2003) SWISS-MODEL: An automated protein homology-modeling server. Nucleic Acids Res. 31, 3381-3385

22 Combet, C., Jambon, M., Deleage, G, and Geourjon, C. (2002) Geno3D: automatic comparative molecular modelling of protein. Bioinformatics 18, 213-214

23 Bates, P. A., Kelley, L. A., MacCallum, R. M. and Sternberg, M. J. (2001) Enhancement of protein modeling by human intervention in applying the automatic programs 3DJIGSAW and 3D-PSSM. Proteins Suppl 5, 39-46

24 Arris, C. E., Boyle, F. T., Calvert, A. H., Curtin, N. J., Endicott, J. A., Garman, E. F., Gibson, A. E., Golding, B. T., Grant, S., Griffin, R. J., Jewsbury, P., Johnson, L. N., Lawrie, A. M., Newell, D. R., Noble, M. E., Sausville, E. A., Schultz, R. and Yu, W. (2000) Identification of novel purine and pyrimidine cyclin-dependent kinase inhibitors with distinct molecular interactions and tumor cell growth inhibition profiles. J. Med. Chem. 43, 2797-2804

25 van Embden, J. D., Cave, M. D., Crawford, J. T., Dale, J. W., Eisenach, K. D., Gicquel, B., Hermans, P., Martin, C., McAdam, R., Shinnick, T. M. and et al. (1993) Strain identification of Mycobacterium tuberculosis by DNA fingerprinting: recommendations for a standardized methodology. J. Clin. Microbiol. 31, 406-409

26 Bishai, W. R., Dannenberg, A. M., Jr., Parrish, N., Ruiz, R., Chen, P., Zook, B. C., Johnson, W., Boles, J. W. and Pitt, M. L. (1999) Virulence of Mycobacterium tuberculosis CDC1551 and H37Rv in rabbits evaluated by Lurie's pulmonary tubercle count method. Infect. Immun. 67, 4931-4934

27 Manca, C., Tsenova, L., Barry, C. E., 3rd, Bergtold, A., Freeman, S., Haslett, P. A., Musser, J. M., Freedman, V. H. and Kaplan, G. (1999) Mycobacterium tuberculosis CDC1551 induces a more vigorous host response in vivo and in vitro, but is not more virulent than other clinical isolates. J. Immunol. 162, 6740-6746 
28 Fleischmann, R. D., Alland, D., Eisen, J. A., Carpenter, L., White, O., Peterson, J., DeBoy, R., Dodson, R., Gwinn, M., Haft, D., Hickey, E., Kolonay, J. F., Nelson, W. C., Umayam, L. A., Ermolaeva, M., Salzberg, S. L., Delcher, A., Utterback, T., Weidman, J., Khouri, H., Gill, J., Mikula, A., Bishai, W., Jacobs Jr, W. R., Jr., Venter, J. C. and Fraser, C. M. (2002) Whole-genome comparison of Mycobacterium tuberculosis clinical and laboratory strains. J. Bacteriol. 184, 5479-5490

29 Warren, R. M., Sampson, S. L., Richardson, M., Van Der Spuy, G. D., Lombard, C. J., Victor, T. C. and van Helden, P. D. (2000) Mapping of IS6110 flanking regions in clinical isolates of Mycobacterium tuberculosis demonstrates genome plasticity. Mol. Microbiol. 37, 1405-1416

30 Fang, Z., Doig, C., Kenna, D. T., Smittipat, N., Palittapongarnpim, P., Watt, B. and Forbes, K. J. (1999) IS6110-mediated deletions of wild-type chromosomes of Mycobacterium tuberculosis. J. Bacteriol. 181, 1014-1020

31 Cole, S. T., Brosch, R., Parkhill, J., Garnier, T., Churcher, C., Harris, D., Gordon, S. V., Eiglmeier, K., Gas, S., Barry, C. E., 3rd, Tekaia, F., Badcock, K., Basham, D., Brown, D., Chillingworth, T., Connor, R., Davies, R., Devlin, K., Feltwell, T., Gentles, S., Hamlin, N., Holroyd, S., Hornsby, T., Jagels, K., Krogh, A., McLean, J., Moule, S., Murphy, L., Oliver, K., Osborne, J., Quail, M. A., Rajandream, M. A., Rogers, J., Rutter, S., Seeger, K., Skelton, J., Squares, R., Squares, S., Sulston, J. E., Taylor, K., Whitehead, S. and Barrell, B. G. (1998) Deciphering the biology of Mycobacterium tuberculosis from the complete genome sequence. Nature 393, 537-544

32 Grundner, C., Gay, L. M. and Alber, T. (2005) Mycobacterium tuberculosis serine/threonine kinases PknB, PknD, PknE, and PknF phosphorylate multiple FHA domains. Protein Sci. 14, 1918-1921

33 Villarino, A., Duran, R., Wehenkel, A., Fernandez, P., England, P., Brodin, P., Cole, S. T., Zimny-Arndt, U., Jungblut, P. R., Cervenansky, C. and Alzari, P. M. (2005) Proteomic identification of $M$. tuberculosis protein kinase substrates: PknB recruits GarA, a FHA domain-containing protein, through activation loop-mediated interactions. J. Mol. Biol. 350, 953-963

34 Molle, V., Zanella-Cleon, I., Robin, J. P., Mallejac, S., Cozzone, A. J. and Becchi, M. (2006) Characterization of the phosphorylation sites of Mycobacterium tuberculosis serine/threonine protein kinases, $\mathrm{PknA}, \mathrm{PknD}, \mathrm{PknE}$, and $\mathrm{PknH}$ by mass spectrometry. Proteomics 6, 3754-3766

35 Senderowicz, A. M. and Sausville, E. A. (2000) Preclinical and clinical development of cyclin-dependent kinase modulators. J. Natl. Cancer Inst. 92, 376-387

36 Gibson, A. E., Arris, C. E., Bentley, J., Boyle, F. T., Curtin, N. J., Davies, T. G., Endicott, J. A., Golding, B. T., Grant, S., Griffin, R. J., Jewsbury, P., Johnson, L. N., Mesguiche, V., Newell, D. R., Noble, M. E., Tucker, J. A. and Whitfield, H. J. (2002) Probing the ATP ribose-binding domain of cyclin-dependent kinases 1 and 2 with O(6)substituted guanine derivatives. J. Med. Chem. 45, 3381-3393

37 Pathak, A. K., Pathak, V., Seitz, L. E., Suling, W. J. and Reynolds, R. C. (2004) Antimycobacterial agents. 1. Thio analogues of purine. J. Med. Chem. 47, 273-276

38 Braendvang, M. and Gundersen, L. L. (2007) Synthesis, biological activity, and SAR of antimycobacterial 2- and 8-substituted 6-(2-furyl)-9-(p-methoxybenzyl)purines. Bioorg. Med. Chem. 15, 7144-7165

39 Morgan, J., Haritakul, R. and Keller, P. A. (2003) Anilinopyrimidines as novel antituberculosis agents. Bioorg. Med. Chem. Lett. 13, 1755-1757

40 Agarwal, A., Srivastava, K., Puri, S. K., Sinha, S. and Chauhan, P. M. (2005) A small library of trisubstituted pyrimidines as antimalarial and antitubercular agents. Bioorg. Med. Chem. Lett. 15, 5218-5221 
41 Narayan, A., Sachdeva, P., Sharma, K., Saini, A. K., Tyagi, A. K. and Singh, Y. (2007) Serine threonine protein kinases of mycobacterial genus: phylogeny to function. Physiol. Genomics 29, 66-75

42 Cohen, P. (2002) Protein kinases--the major drug targets of the twenty-first century? Nat. Rev. Drug Discov. 1, 309-315

43 Huse, M. and Kuriyan, J. (2002) The conformational plasticity of protein kinases. Cell 109, 275-282

44 Johnson, L. N., Noble, M. E. and Owen, D. J. (1996) Active and inactive protein kinases: structural basis for regulation. Cell 85, 149-158

45 Daffe, M. and Draper, P. (1998) The envelope layers of mycobacteria with reference to their pathogenicity. Adv. Microb. Physiol. 39, 131-203

46 Briken, V., Porcelli, S. A., Besra, G. S. and Kremer, L. (2004) Mycobacterial lipoarabinomannan and related lipoglycans: from biogenesis to modulation of the immune response. Mol. Microbiol. 53, 391-403 


\section{Figure legends}

Figure 1. (A) Organization of the region of insertion containing the embR2 locus in $M$. tuberculosis CDC1551 relative to strain H37Rv. The thick line represents the 4.4-kb insertion region. The coordinates of the insertion region and those of the embR2 gene are indicated, according to [28]. Arrows represent the direction of transcription. The embR2 gene is shown in grey. (B) Sequence alignment of EmbR from the strain H37Rv and EmbR2 from the strain CDC1551. Identical residues are shown in black. Arrowheads indicate the position of the three highly conserved FHA residues (Arg312, Ser326 and Asn348 with regard to the EmbR sequence). (C) Superposition of the C $\alpha$ trace of EmbR (Yellow, PDB: 2FF4) with those of the homology models of EmbR2 (cyan - SWISSMODEL, magenta - 3DJIGSAW, blue GENO3D). Shown in gray sticks is the phosphopeptide bound to the FHA domain of EmbR. Inset: region of the 1-residue deletion in the FHA domain, leading to discrepancies in backbone conformation of the different homology models.

Figure 2. In vitro phosphorylation of EmbR and EmbR2 by PknH. His-tagged fusion proteins were purified from E. coli C41(DE3) carrying either pET28a-embR, pET28a-embR2 or pET28a-embR2(R204T/A208T). Purified GST-PknH was incubated with $3 \mu \mathrm{g}$ of either purified His-tagged EmbR, EmbR2 or EmbR2-R204T/A208T in the presence of $\left[\gamma-{ }^{33} \mathrm{P}\right] \mathrm{ATP}$ for $15 \mathrm{~min}$ at $37^{\circ} \mathrm{C}$. Samples were separated by SDS-PAGE and detected by Coomassie blue staining (upper panels) and then exposed overnight to a film and visualized by autoradiography (lower panels). Positions of PknH, EmbR and EmbR2 are indicated.

Figure 3. In vitro phosphorylation of EmbR and EmbR2 by PknE and PknF. (A) Purified GST-PknE and GST-PknF were incubated with either His-tagged EmbR (left panels) or Histagged-EmbR2 (right panels) with $\left[\gamma_{-}{ }^{33} \mathrm{P}\right] \mathrm{ATP}$. Samples were separated by SDS-PAGE and visualized following Coomassie blue staninig (upper panels) or autoradiography after exposure to a film (lower panels). (B) Phosphoamino acid content of the Pkn-phosphorylated EmbR/EmbR2. EmbR and EmbR2 were phosphorylated in vitro in presence of either GSTPknE, GST-PknF or GST-PknH and $\left[\gamma-{ }^{33} \mathrm{P}\right]$ ATP, analyzed by SDS-PAGE, electroblotted onto an Immobilon PVDF membrane, excised and hydrolyzed in acid. The phosphoamino acids thus liberated were separated by electrophoresis in the first dimension (1D) and ascending chromatography in the second dimension (2D). After migration, radioactive molecules were 
detected by autoradiography. Authentic phosphoserine (P-Ser), phosphothreonine (P-Thr), and phosphotyrosine (P-Tyr) were run in parallel as internal standard controls, and visualized by ninhydrin staining.

\section{Figure 4. Dose-response inhibition of PknH autokinase activity by O6-} cyclohexylmethylguanine or EmbR2. (A) O6-cyclohexylmethylguanine inhibits PknD, PknE and PknH activity. Autophosphorylation inhibition by O6-cyclohexylmethylguanine was evaluated against eight out of the eleven M. tuberculosis STPKs by incubating the kinases with $\left[\gamma_{-}{ }^{33} \mathrm{P}\right] \mathrm{ATP}$ for $20 \mathrm{~min}$ at $37^{\circ} \mathrm{C}$ in the absence (-) or presence $(+)$ of $50 \mu \mathrm{M}$ of inhibitor. Samples were separated by SDS-PAGE and visualized by autoradiography. (B) Purified GST-PknH (0.3 $\mu \mathrm{g}$ ) were incubated with increasing concentrations of either O6-cyclohexylmethylguanine (up to $100 \mu \mathrm{M}$ ) or EmbR2 (up to $3 \mu \mathrm{g}$ ) in the presence of $\left[\gamma_{-}{ }^{33} \mathrm{P}\right] \mathrm{ATP}$ for $20 \mathrm{~min}$ at $37^{\circ} \mathrm{C}$. Samples were separated by SDS-PAGE. The upper panels correspond to the Coomassie blue-stained gels, showing the presence of comparable amounts of $\mathrm{PknH}$ in each assay, the middle panels correspond to the corresponding autoradiograms, whereas the lower panels reflect densitometric analysis. In the case of EmbR2, each bar represent the mean of values from three independent experiments.

Figure 5. PknH-dependent phosphorylation of EmbR is inhibited by EmbR2. Equal amounts of purified GST-PknH $(0.3 \mu \mathrm{g})$ and EmbR $(1 \mu \mathrm{g})$ were incubated with increasing concentrations (up to $3 \mu \mathrm{g}$ ) of EmbR2 with $\left[\gamma_{-}{ }^{33} \mathrm{P}\right] \mathrm{ATP}$ for $20 \mathrm{~min}$ at $37^{\circ} \mathrm{C}$. Samples were separated by SDS-PAGE and the effect of EmbR2 on PknH and EmbR phosphorylation was visualized by autoradiography. The upper panels represent the corresponding autoradiograms, whereas the lower panels reflect densitometric analysis. In a control experiment, EmbR2 was replaced by GST. 
Table 1 : Phosphopeptide binding of EmbR2. Intensity of Trp fluorescence emission at 330 $\mathrm{nm}$ was evaluated as a function of concentration of three different PknH-derived phosphopeptides (DEKLPTQLGT containing the pThr170, TQLGPTAVGT containing the pThr174, and DSAGpTLVSS containing the pThr222) as well as the Rad53p-ligand (SLEVpTEADT). The $K_{d}$ values are as indicated.

$\operatorname{PknH}$\begin{tabular}{cl} 
Phosphopeptide sequence & $\mathbf{K}_{\mathbf{d}}($ in $\mu \mathbf{M})$ \\
\hline DEKLFTQLGT & $18.3 \pm 4.4$ \\
TQLGpTAVGT & $21.1 \pm 4.1$ \\
DSAGPTLVSS & $11.9 \pm 1.7$ \\
\hline SLEVPTEADT & $17.1 \pm 1.4$
\end{tabular}

Licenced copy. Copying is not permitted, except with prior permission and as allowed by law. (C) 2007 The Authors Journal compilation (C) 2007 Biochemical Society 


\section{Figure 1}

A

M. tuberculosis CDC1551

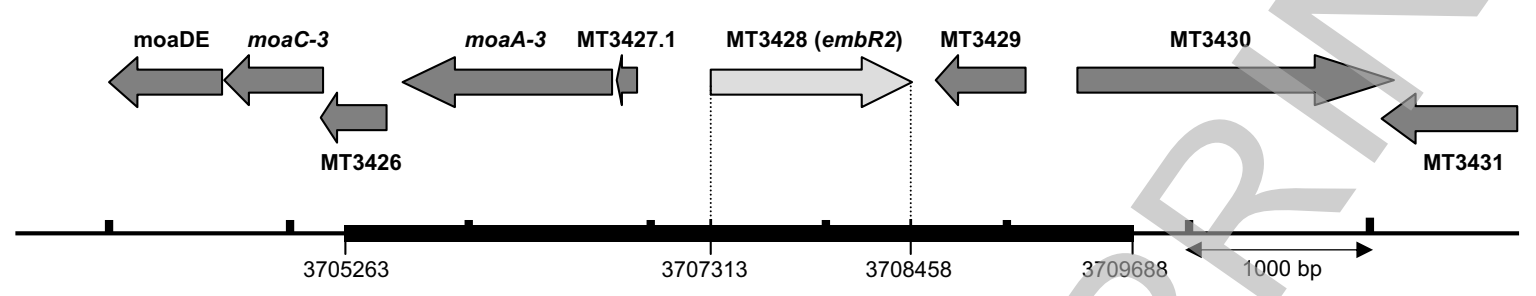

B

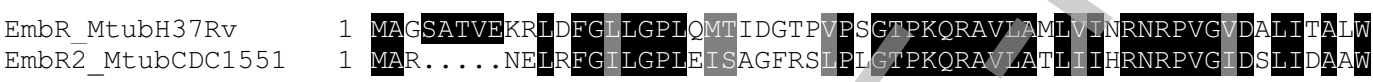

$\begin{array}{ll}\text { EmbR_MtubH37Rv } & 61 \text { EEWPPSGARASIHSYVSNLRKLIGGAGIDPRVIAAAPPGYRLSIPDNTCDLGREVAEKT } \\ \text { EmbR2_MtubCDC1551 } & 56 \text { EQDRPEGSRATVYTYVSNLRRLVSTTGADSHSILASAPPGYRLAVADNQYDVAREISQRS }\end{array}$

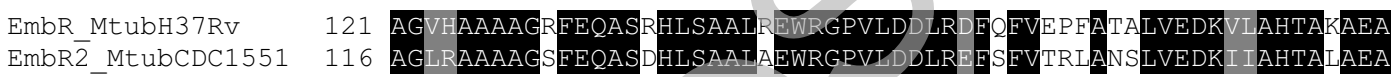

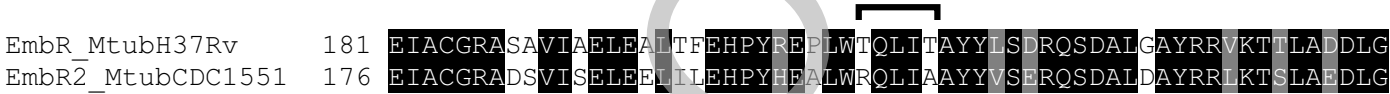

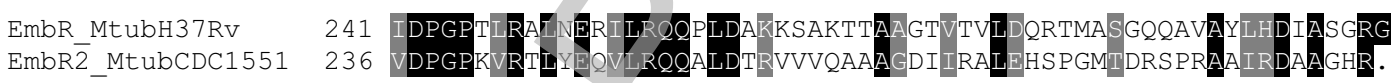

$\begin{array}{lll}\text { EmbR_MtubH37RV } & 301 \text { YPIOAAATRIGRLHDNDIVIDSANVSRHHAVIVDTGTNYVINDLRSSNGVHVEHERIRSA } \\ \text { EmbR2_MtubCDC1551 } & 295 \text { SPLGRLPLRIGRSKSNDMVIPDGKVSPYHAVIVNTGESEMITDLRSVNGVYVRGRIATT }\end{array}$

$\begin{array}{ll}\text { EmbR_Mt MbH37Rv } & 361 \text { VTLNDGDHIRICDHFETFQISAGTHGGT } \\ \text { EmbR2_MtubCDC1551 } & 355 \text { ATLNDGDHIRIGDHELTEEVIPHESGR. }\end{array}$

Licenced copy. Copying is not permitted, except with prior permission and as allowed by law.

(C) 2007 The Authors Journal compilation (C) 2007 Biochemical Society 


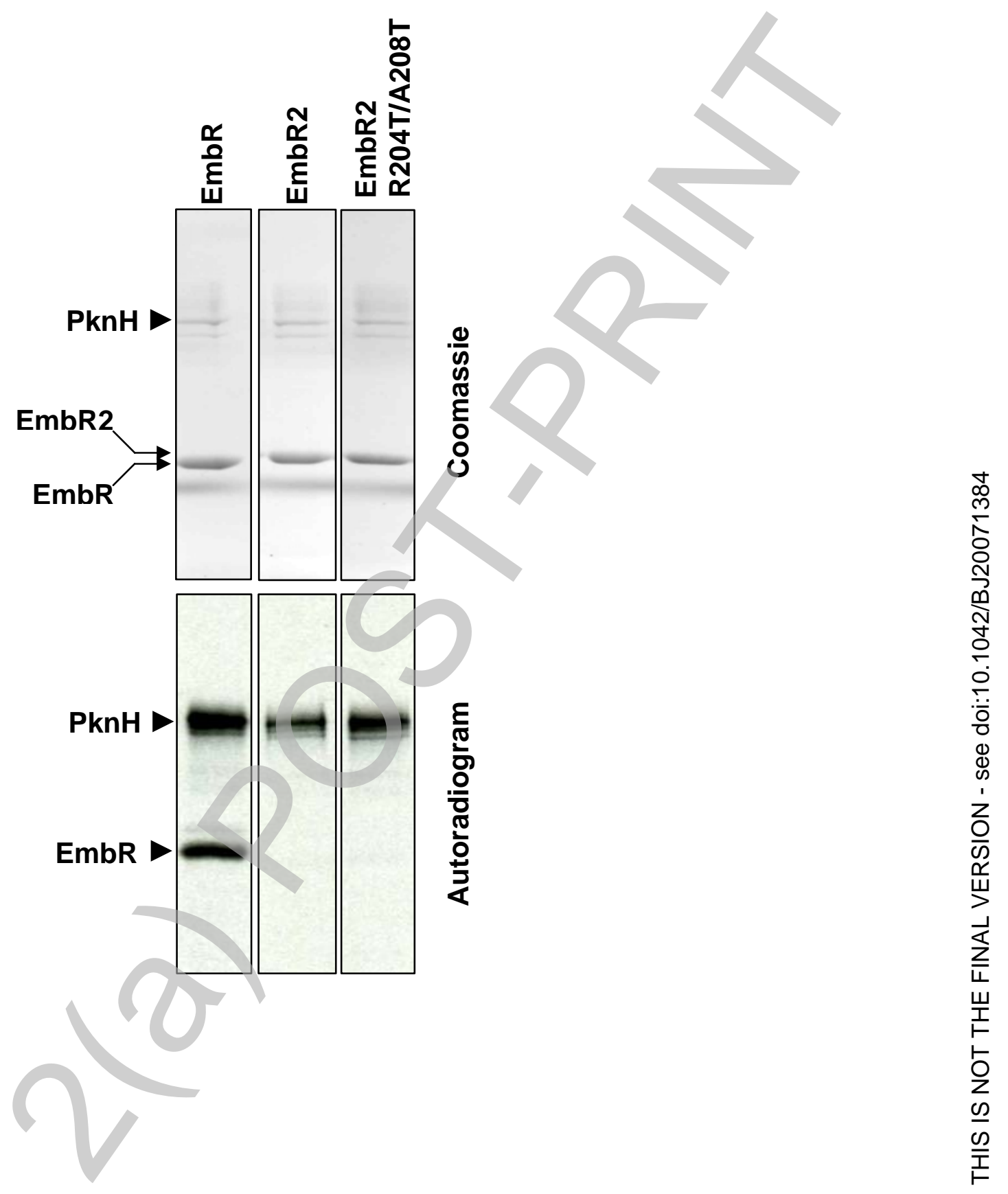


Figure 3

A

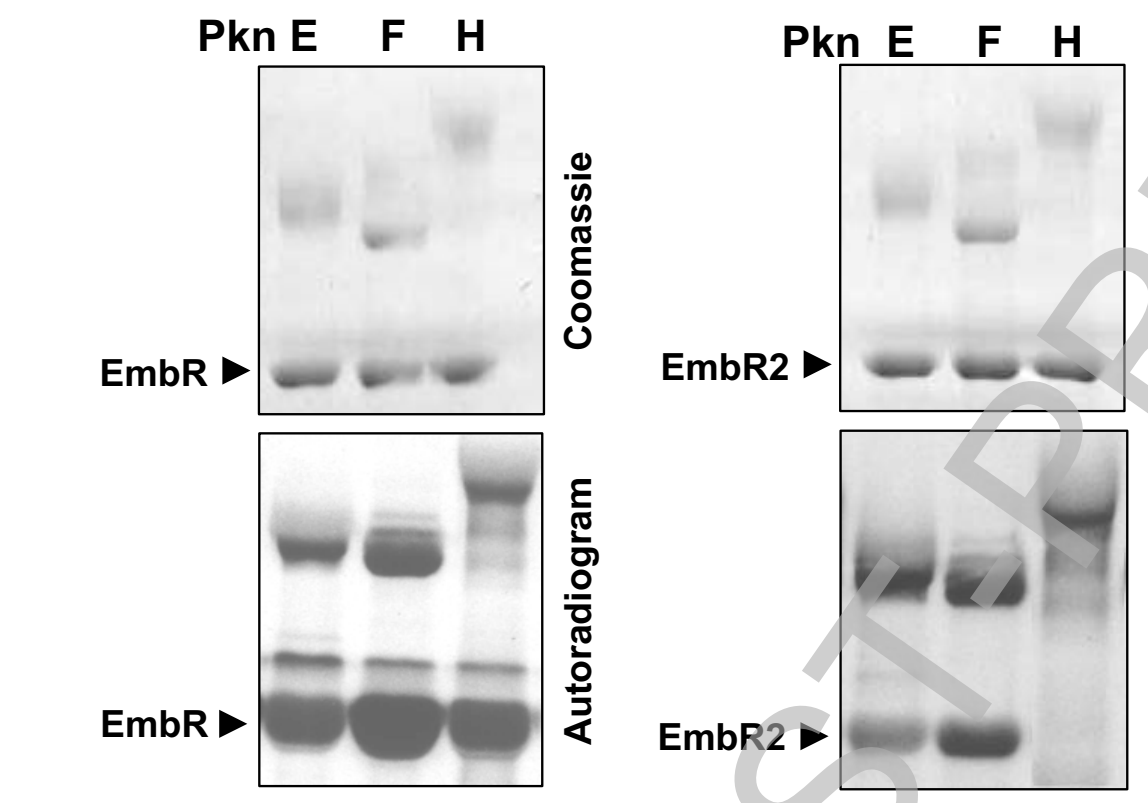

B
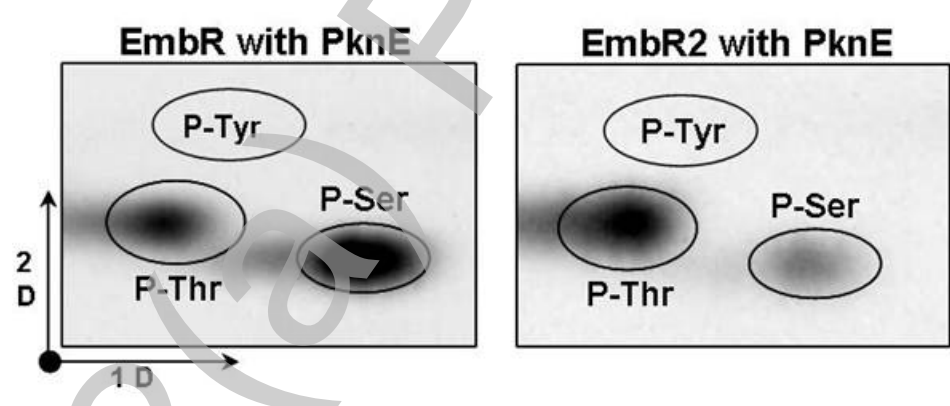

EmbR with PknF

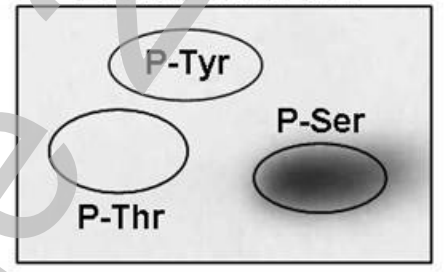

EmbR2 with PknF

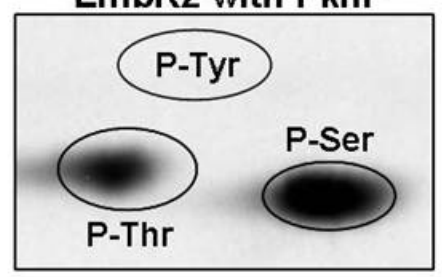

EmbR with PknH

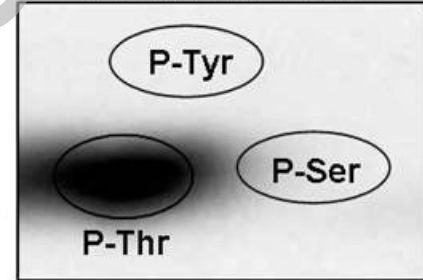

Licenced copy. Copying is not permitted, except with prior permission and as allowed by law. (C) 2007 The Authors Journal compilation (C) 2007 Biochemical Society 
A

Figure 4

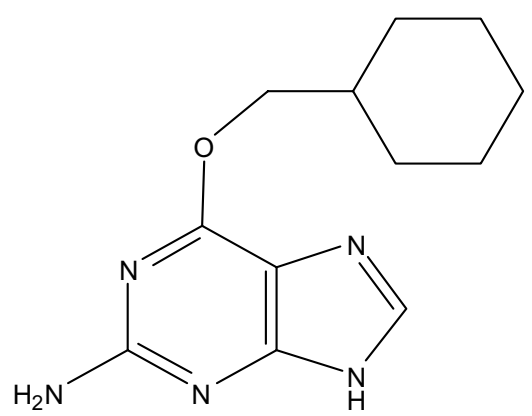

O6-cyclohexylmethylguanine

O6-cyclohexylmethylguanine
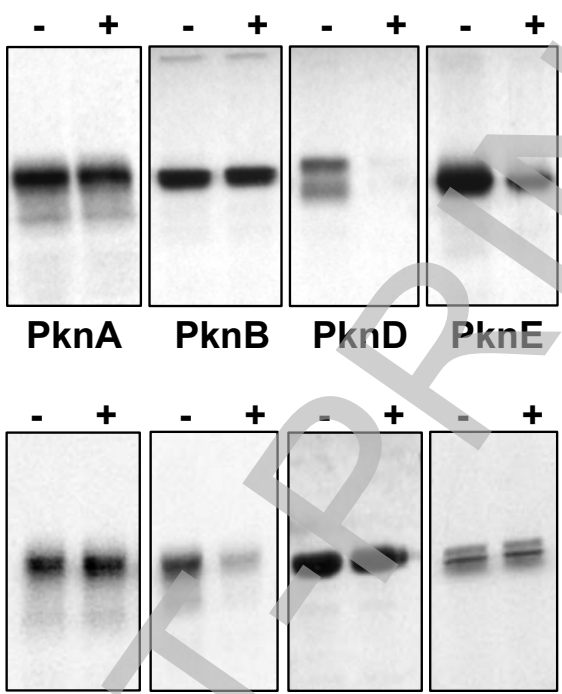

PknF PknH PknK PknL

B

O6-cyclohexylmethylguanine

EmbR2
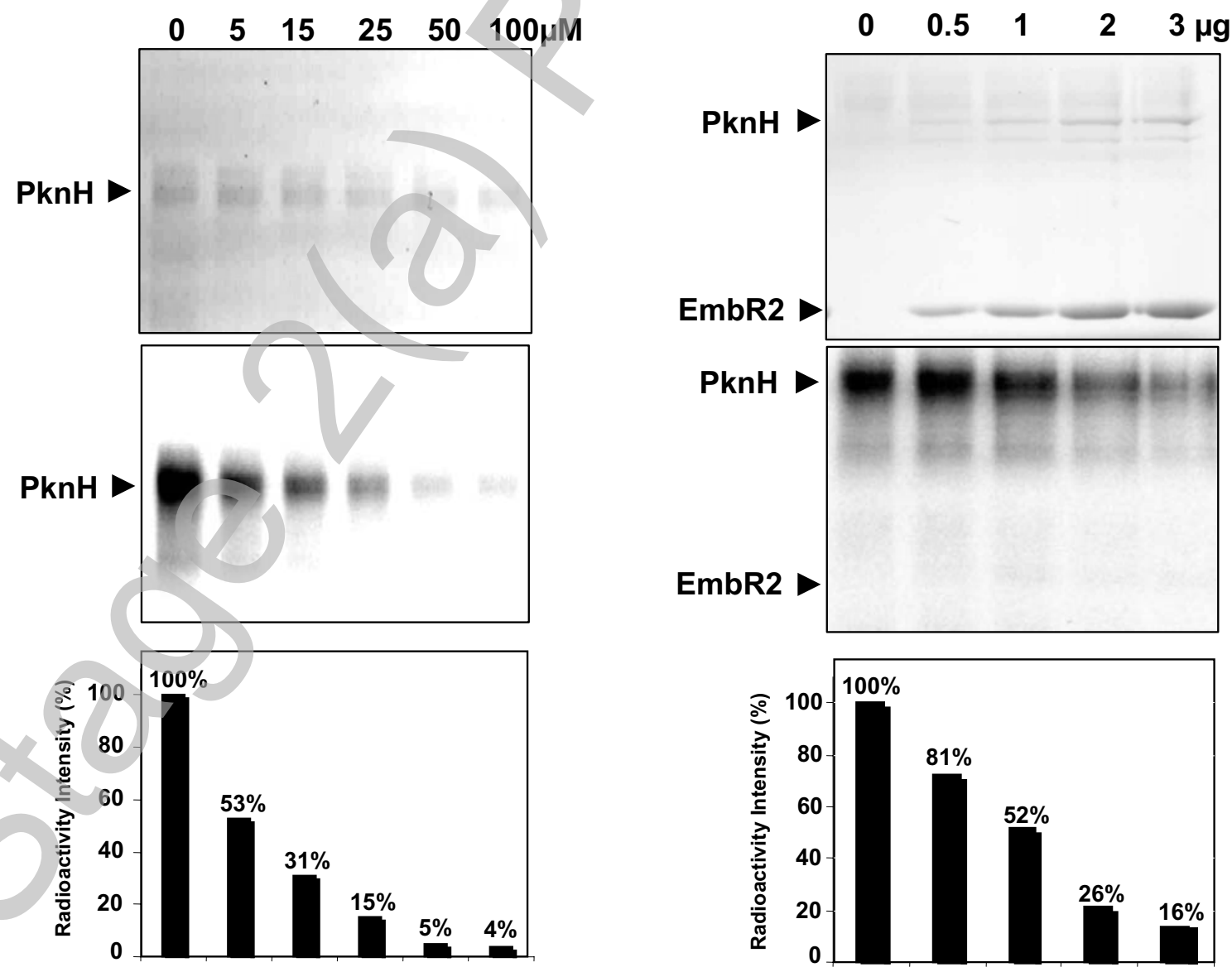

Licenced copy. Copying is not permitted, except with prior permission and as allowed by law. (C) 2007 The Authors Journal compilation (C) 2007 Biochemical Society 


\section{Figure 5}
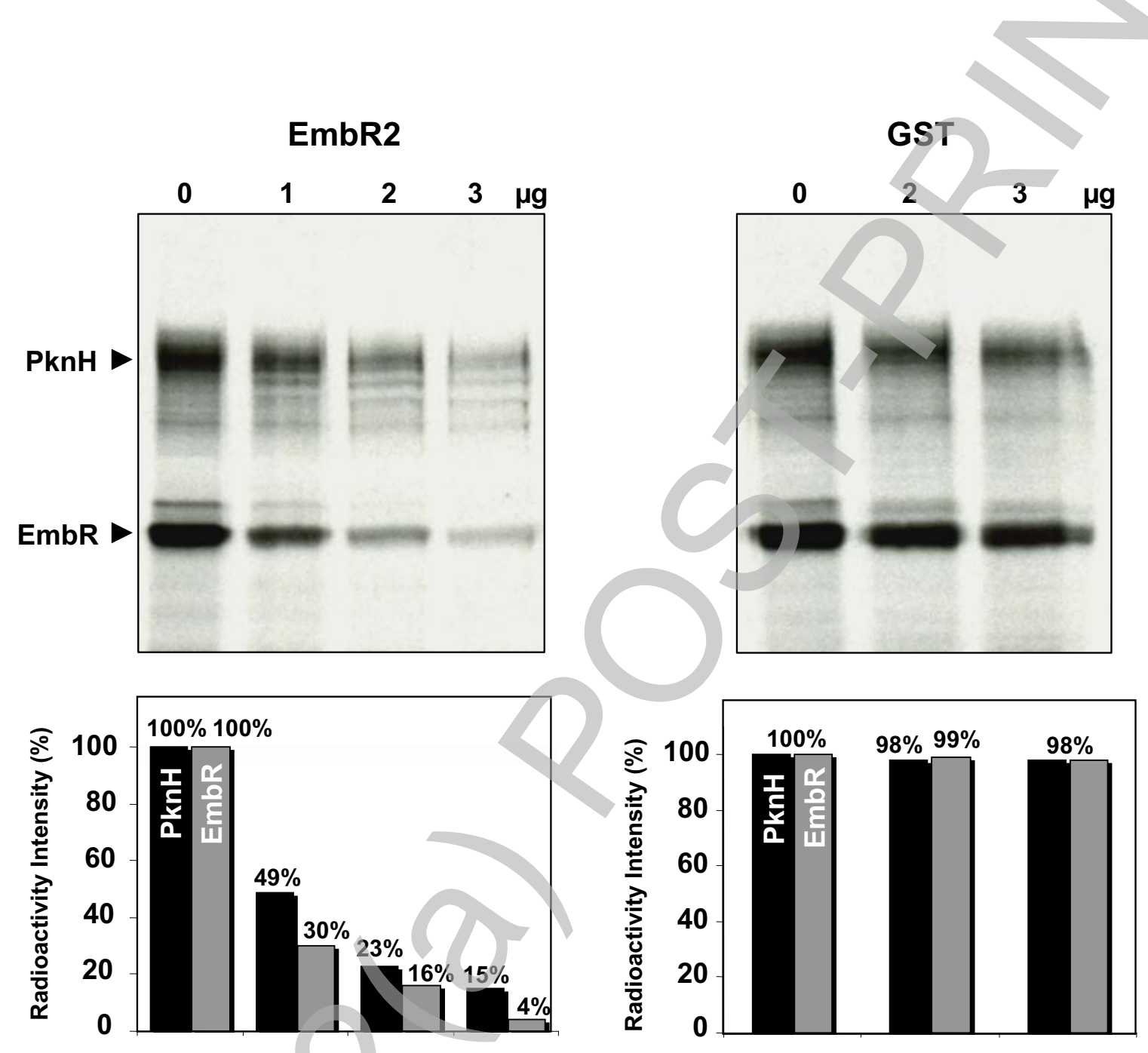